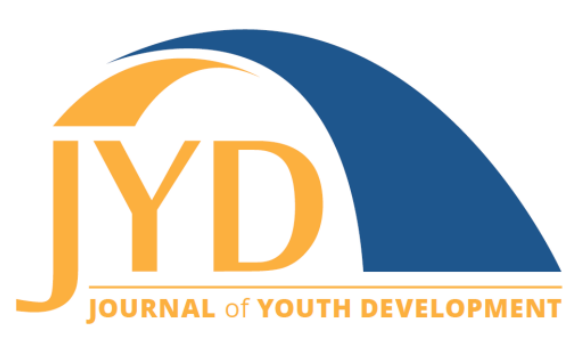

http://jyd. pitt. edu/ | Vol. 14 Issue 3 DOI 10.5195/jyd.2019.662 | ISSN 2325-4017 (online)

\title{
Self-Determination Through Circus Arts: Exploring Youth Development in a Novel Activity Context
}

\author{
Jennifer P. Agans \\ Pennsy/vania State University \\ jxa912@psu.edu \\ Jacqueline L. Davis \\ University of British Columbia \\ jad310@mail.harvard.edu

\section{Spyridoula Vazou} \\ Iowa State University \\ svazou@iastate.edu

\section{Tal Jarus} \\ University of British Columbia \\ tal.jarus@ubc.ca
}

\begin{abstract}
Youth development takes place in many contexts, with different resulting participant outcomes. Broadening the scope of research to include non-traditional contexts such as youth circus arts programs, which are both similar to and different from other out-of-school-time contexts, may promote better understanding of the ways in which these programs impact youth development. The present study examined the prevalence of support for basic psychological needs and positive developmental outcomes among youth circus program participants. Single time-point quantitative surveys were completed by 111 youth members of the American Youth Circus Organization (62\% female), ranging in age from 10 to 21. Results indicated psychological need support predicted positive developmental outcomes. Relatedness was the strongest predictor of intrinsic motivation, affect, and positive youth development. This study illustrates a novel way in which physical activity and youth development can be integrated in youth programs. It contributes to the understanding of youths' self-determined motivation in physical activities and points to the importance of examining under-studied youth activity contexts such as circus arts.
\end{abstract}

Key words: out-of-school time, positive youth development, youth circus, self-determination, physical activity

(cc) $\mathbf{E Y}$ New articles in this journal are licensed under a Creative Commons Attribution 4.0 License. This journal is published by the University Library System, University of Pittsburgh and is cosponsored by the University of Pittsburgh Press. The Journal of Youth Development is the official peer-reviewed publication of the National Association of Extension 4-H Agents and the National AfterSchool Association. 


\section{Self-Determination Through Circus Arts}

\section{Background}

Youth involvement in organized sport has been studied extensively (e.g., Evans et al., 2017; Vazou, Ntoumanis, \& Duda, 2006), but many related activities remain under-explored. Lifestyle sports (e.g., rock climbing, skateboarding) and physical activities involving creative expression (e.g., dance, circus arts) have received relatively little attention (with some exceptions; e.g., Quested \& Duda, 2011), despite large numbers of participating youth. For example, a recent survey of over 120 organizations teaching circus arts across the United States, including summer camps, independent circus studios, and after-school programs, reported approximately 14,000 youth participants in their circus education programs in 2018 (American Youth Circus / American Circus Educators, 2018). As these non-sport activities become more popular, there is a need to understand the developmental outcomes associated with participation and the extent to which they might serve as youth development programs. In addition, as most children and adolescents are not active enough to meet minimum physical activity guidelines (Song, Carroll, \& Fulton, 2013), it is important to explore physical activity contexts that may foster intrinsic motivation to participate.

\section{Youth Development and Motivation in Physical Activities}

Self-determination theory (SDT; Deci \& Ryan, 2000) has been widely used to study youth involvement in sport and other physical activity contexts (e.g., Gagne, Ryan, \& Bargmann, 2003; Standage, Duda, \& Ntoumanis, 2005; 2006). SDT posits three "basic psychological needs" which must be met for human thriving and positive development: autonomy (the need to make one's own decisions in life), competence (the need to feel able to accomplish tasks and goals), and relatedness (the need to feel connection to other people; Deci \& Ryan, 2000). SDT maintains that these basic psychological needs can be supported or thwarted in any context, and need fulfillment can vary widely from one activity context to another (Teixeira, Carraça, Markland, Silva, \& Ryan, 2012). Thus, it is important to identify physical activity contexts that support these basic needs.

Self-determined motivation is also associated with increased physical activity (Teixeira et al., 2012), and higher levels of autonomy, competence, and relatedness are linked to reduced attrition from sport (Balish, McLaren, Rainham, \& Blanchard, 2014). In addition, relatedness support in physical education contexts, fostered by particular teacher behaviors, has been shown to promote engagement, self-efficacy, and motivation, as well as interest in continuing or increasing physical activity participation (Sparks, Dimmock, Whipp, Lonsdale, \& Jackson, 


\section{Self-Determination Through Circus Arts}

2015). Such contexts are more likely to foster intrinsic motivation and promote positive developmental outcomes including positive affect and willingness to attempt challenging tasks (Standage et al., 2005). Thus, it may be expected that youth whose needs are supported in physical activity contexts are also more likely to enjoy being active and continue participating in physical activities.

While existing research suggests that competence and autonomy satisfaction are linked to increased physical activity (Reinboth, Duda, \& Ntoumanis, 2004; Shen, McCaughtry, \& Martin, 2007), research on relatedness satisfaction in youth recreational physical activity contexts is scarce (Teixeira et al., 2012). However, relatedness support in physical education classes has been shown to promote interest in continued physical activity participation (Sparks et al., 2015). In addition, activities that provide relatedness support may be important promoters of youth physical activity behavior, as youth rely strongly on peers' acceptance and support as a source of competence evaluation (Smith, 2003). Similarly, drawing from the tenets of Achievement Goal Theory (Nicholls, 1989), the emphasis placed on cooperation versus peer competition by the activity context is crucial for the way competence is evaluated. A more task-involving peer climate (associated with positive affect, intrinsic motivation, and enjoyment; Harwood, Keegan, Smith, \& Raine, 2015; Vazou et al., 2006) will likely nurture positive social interactions and cooperation. Thus, physical activity contexts that foster relatedness and whole-child development (e.g., activities that are enjoyable, supportive, and cognitively engaging; Diamond, 2015) may be especially effective in promoting youth physical activity.

Because physical activity contexts that are supportive of basic psychological needs can help youth stay active (Balish et al., 2014; Shen et al., 2007; Teixeira et al., 2012), it is important to identify more programs with those characteristics. Unfortunately, the emphasis of past studies on sport (e.g., Reinboth et al., 2004) and physical education contexts (e.g., Standage, Duda, \& Ntoumanis, 2003, 2005, 2006) has left the fulfilment and support of basic psychological needs in non-sport physical activity contexts, such as circus arts, unexplored.

\section{Circus as a Youth Development Context}

Youth circus, defined as "circus created and performed by youth, as opposed to entertainment devised for youth," (Ott, 2005, p. 5) emerged in the United States in the 1970s as part of the community-based "new circus" movement. Like many youth development programs (e.g., Lerner et al., 2012; Roth \& Brooks-Gunn, 2003), and unlike many youth sport programs (e.g., Neely, McHugh, Dunn, \& Holt, 2017), circus arts programs generally feature a cooperative 


\section{Self-Determination Through Circus Arts}

setting, mixed-gender activities, and acceptance of all youth irrespective of body type, initial competence, or other limitations (Bolton, 2004; McCutcheon, 2003; Ott, 2005). This inclusive context is important for positive youth development (PYD; Lerner et al., 2012; Roth \& BrooksGunn, 2003). In fact, a recent evaluation of youth circus programs conducted by the David P. Weikart Center for Youth Program Quality found that these programs consistently met standards for exemplary youth development programs (Smith, Roy, Peck, \& Macleod, 2017). Participants in youth circus programs demonstrated significant growth in social and emotional skills over the course of their program participation (Smith et al., 2017), which suggests that youth circus arts may be considered a type of youth development program.

Within this youth development setting, circus arts programs maintain an emphasis on building challenging physical skills, similar to the approach taken in sport-based youth development programs (e.g., Perkins \& Noam, 2007) but with an artistic, rather than a competitive orientation. This lack of emphasis on competition may also contribute to supporting youth basic psychological needs (Vallerand, 2007).

The factors that make youth circus unique within physical activity settings may provide different affordances for the satisfaction of basic psychological needs than sport programs. For example, youth circus programs generally allow youth to explore a wide variety of activities (e.g., acrobatics, juggling, clowning, wire-walking, trapeze) and thus may support autonomy (e.g., McCutcheon, 2003) more than single-sport programs. In addition, because most youth have limited experience with circus, more explicit competence support is often provided in these programs (e.g., Heller \& Taglialatela, 2018; Kiez, 2015) than might be offered in traditional sports. Finally, the collaboration and trust required to produce a circus (Cadwell, 2018) may further promote relatedness. Existing studies of youth circus cite a wide range of developmental benefits, including growth in perseverance, belonging, and self-esteem (Heller \& Taglialatela, 2018; McCutcheon, 2003; Ott, 2005; Woodhead, 2002). These outcomes align with youth development outcomes such as grit (Duckworth, Peterson, Matthews, \& Kelly, 2007) and the 5 Cs model of PYD, which focuses on Competence, Confidence, Caring, Character, and Connection (Lerner et al., 2012).

Because prior research suggests that youth psychosocial experiences in sport-based physical activities vary based on activity characteristics (Evans et al., 2017), it would be useful to extend this investigation to non-sport activities. Youth circus has been increasingly integrated into education (Kiez, 2015), recreation and social services (Sugarman, 2001), and therapeutic 


\section{Self-Determination Through Circus Arts}

contexts (Maglio \& McKinstry, 2008; Spiegel, Breilh, Campaña, Marcuse, \& Yassi, 2015), thus further study of its impact on youth development is warranted.

\section{Study Goals}

The present study examined the extent to which youth circus serves as a need-supportive physical activity context and tested for associated youth development outcomes. In line with prior studies of basic psychological need satisfaction in the context of physical activity (Standage et al., 2005), we hypothesized that youth circus may satisfy the needs for autonomy, competence, and relatedness in young people, and that participants would report being intrinsically motivated to do circus. We also hypothesized, based on the prior research on youth circus participant outcomes (e.g., Ott, 2005; Smith et al., 2017; Woodhead, 2002), that psychological need satisfaction in the circus context would positively predict other positive outcomes such as perseverance (operationalized as grit and concentration; Duckworth et al., 2007; Standage et al., 2005) and PYD (Geldhof et al., 2014; Lerner et al., 2012). Finally, we expected that satisfaction of basic psychological needs would also positively predict positive affect, and negatively predict negative affect, as these outcomes have been observed in other physical activity contexts (Ntoumanis, 2005).

This study also examined gender and age differences on the measured motivational outcomes in youth circus, an area of research that is relatively new with little known about youth motivation in circus programs. Prior research in other contexts indicates that children of different ages may rely on different sources of information to assess competence (Horn, 2004) and that, compared to males, female athletes may be more motivated by improving their own skills than by seeking to be better than other athletes (Hanrahan \& Cerin, 2009). Thus, we expected that although satisfaction of the psychological needs of autonomy, competence, and relatedness would predict positive outcomes (e.g., grit, concentration, positive affect, PYD), youth of different ages and genders might report different levels of need satisfaction and developmental outcomes.

Through this examination of youth development in the circus arts context, our aim was to better understand the breadth of ways in which non-sport physical activity programs may impact youth development, and to broaden the literature on youth physical activity programs beyond the current emphasis on sport. In addition, as many youth programs include a wide range of recreational activities, our study may be of value to practitioners and program planners 


\section{Self-Determination Through Circus Arts}

by illustrating a novel way in which physical activity and youth development can be integrated in youth programs.

\section{Method}

\section{Participants and Procedure}

Participants were 111 youth, ages 10-21 ( $M=15.77 ; S D=3.53)$, who were recruited through the American Youth Circus Organization (AYCO). Most participants (62\%, $n=69)$ were female, $31 \%(n=34)$ were male, and $7 \%(n=8)$ did not provide information or stated that they preferred not to answer the question about gender. Single time-point quantitative surveys were administered to youth at a national AYCO festival, and the study was opened online to AYCOmember youth circus programs for a few months after the festival. Participants' experience in circus ranged from 6 months to 17 years, and their circus involvement included afterschool programs, summer camps, and clubs. The study was approved by the Institutional Behavioral Review Board and informed consent was obtained from the participants and their parents or guardians.

\section{Measures}

Descriptive statistics and scale reliability data for each measure are shown in Table 1. All scales were modified to include the term "circus" as a program descriptor. With regard to psychological need support, Autonomy was measured using six items from Standage, Duda, and Ntoumanis (2003; 2005; e.g., "In my circus program, I feel I do circus because I want to"). Competence was measured using five items from McAuley, Duncan, and Tammen (1989; e.g., "I think I am pretty good at circus"). Relatednesswas measured using the stem "With the other students in my circus program, I feel . . . " followed by five adjectives including "supported," and "safe" (Richer \& Vallerand, 1998). Autonomy supportwas measured using 15 items from Williams and Deci (1996; e.g., "My circus teacher/coach listens to how I would like to do things"). Competence support and Relatedness support were assessed using the stem, "In my circus program" followed by four items for competence, e.g., "my circus teacher/coach makes me feel like I am good at circus" and five items for relatedness, e.g., "I feel that the circus teacher/coach is friendly towards me" (Standage et al., 2005). 
Journal of Youth Development | http://jyd.pitt.edu/ | Vol. 14 Issue 3 DOI 10.5195/jyd.2019.662 Self-Determination Through Circus Arts

Table 1. Internal Consistency (Cronbach's Alpha) and Descriptive Statistics for Each Measure.

\begin{tabular}{|l|c|c|c|c|c|}
\hline Measure & $\mathbf{N}$ & $\mathbf{a}$ & $\boldsymbol{M}$ & \multicolumn{1}{|c|}{ SD } & Scale range \\
\hline Autonomy & 110 & 0.71 & 6.06 & 0.79 & $1-7$ \\
\hline Competence & 110 & 0.83 & 5.90 & 0.81 & $1-7$ \\
\hline Relatedness & 110 & 0.90 & 6.07 & 0.98 & $1-7$ \\
\hline Autonomy support & 103 & 0.95 & 6.02 & 0.93 & $1-7$ \\
\hline Competence support & 103 & 0.81 & 6.32 & 0.77 & $1-7$ \\
\hline Relatedness support & 103 & 0.77 & 6.35 & 0.68 & $1-7$ \\
\hline Intrinsic motivation & 106 & 0.68 & 6.68 & 0.43 & $1-7$ \\
\hline Concentration & 104 & 0.73 & 4.22 & 0.45 & $1-5$ \\
\hline Positive affect & 104 & 0.80 & 4.42 & 0.58 & $1-5$ \\
\hline Negative affect & 104 & 0.66 & 1.67 & 0.54 & $1-5$ \\
\hline PYD & 105 & 0.75 & 4.03 & 0.39 & $1-5$ \\
\hline Grit & 105 & 0.71 & 3.47 & 0.48 & $1-5$ \\
\hline
\end{tabular}

For youth outcomes, intrinsic motivation was measured using the stem "I take part in a circus program . . . " followed by four reasons (e.g., "because circus is fun"; Goudas, Biddle, \& Fox, 1994). Concentration was measured using six items modified to specify the circus context (e.g., "I get easily distracted during circus" reversed; Standage et al., 2005). Positive and negative affect were measured by the frequency of nine feelings (e.g., happy, angry) based on the stem "In my circus classes I feel . . ." (Ebbeck \& Weiss, 1998). Positive youth development was measured using the 17-item version of the 5 Cs of PYD (Geldhof et al., 2014), and Grit was measured using 12 more general items (e.g., "Setbacks don't discourage me"; Duckworth et al., 2007).

\section{Results}

This study involved descriptive assessments of psychological need satisfaction and support and youth development outcomes (e.g., intrinsic motivation, concentration, grit, positive affect, and PYD) among youth circus participants, as well as hierarchical regression analyses examining the 


\section{Self-Determination Through Circus Arts}

relations between psychological needs and youth development outcomes. Data were analyzed using SPSS.

\section{Descriptive Statistics}

We hypothesized that youth circus programs may provide satisfaction of the needs for autonomy, competence, and relatedness, and that this need satisfaction would produce intrinsic motivation, concentration, grit, positive affect, and PYD, and low levels of negative affect. Descriptive results indicated that youth in circus programs exhibited each of these outcomes in the expected directions (i.e., average responses for positive outcomes were above the scale mid-points and neared the extreme upper values; see Table 1). Thus, we next examined whether there were gender or age differences in these outcomes, and then addressed our main hypothesis of whether youth development outcomes were related to the satisfaction of basic psychological needs in youth circus.

\section{Gender/Age Differences}

Differences in outcomes were assessed by participant gender and age (both main effects and interactions), with age being divided into four categories: 10-12, 13-15, 16-18, and 19-21. Significant gender differences were observed in concentration, and age differences were observed in autonomy, competence, and positive affect (see Table 2). Age-gender interaction effects were also observed for competence and positive affect (see Figure 1). No differences were observed by how long youth had been involved in circus arts, but there were differences by the age at which they started circus for autonomy $\left[F(1,101)=4.93, p<.05, \eta^{2}=.05\right]$ and competence $\left[F(1,101)=4.76, p<.05, \eta^{2}=.05\right]$ such that youth who started at age 12 or younger reported lower levels of autonomy and higher levels of competence than youth who started circus in their teens. 
Journal of Youth Development | http://jyd.pitt.edu/ | Vol. 14 Issue 3 DOI 10.5195/jyd.2019.662 Self-Determination Through Circus Arts

Table 2. Gender and Age Differences in Youth Development Outcomes: Main Effects

\begin{tabular}{|c|c|c|c|}
\hline & Group & Mean & ANOVA \\
\hline \multicolumn{3}{|l|}{ Autonomy } & \multirow{5}{*}{$\begin{array}{l}F(3,95)=4.35 \\
p<.01 \\
\eta^{2}=.12\end{array}$} \\
\hline & $10-12$ years & $5.64^{a}$ & \\
\hline & $13-15$ years & 6.05 & \\
\hline & $16-18$ years & $6.16^{b}$ & \\
\hline & $19-21$ years & $6.47^{b}$ & \\
\hline \multicolumn{3}{|l|}{ Competence } & \multirow{5}{*}{$\begin{array}{l}F(3,95)=3.65 \\
p<.05 \\
\eta^{2}=.10\end{array}$} \\
\hline & $10-12$ years & $6.34^{a}$ & \\
\hline & $13-15$ years & 5.88 & \\
\hline & $16-18$ years & $5.70^{b}$ & \\
\hline & $19-21$ years & $5.67^{b}$ & \\
\hline \multirow[t]{5}{*}{ Positive affect } & & & \multirow{5}{*}{$\begin{array}{l}F(3,94)=3.10 \\
p<.05 \\
\eta^{2}=.09\end{array}$} \\
\hline & $10-12$ years & $4.74^{a}$ & \\
\hline & $13-15$ years & $4.33^{b}$ & \\
\hline & $16-18$ years & $4.32^{b}$ & \\
\hline & 19-21 years & $4.36^{b}$ & \\
\hline \multirow[t]{3}{*}{ Concentration } & & & \multirow{3}{*}{$\begin{array}{l}F(1,94)=4.03 \\
p<.05 \\
\eta^{2}=.04\end{array}$} \\
\hline & Male & $4.09^{a}$ & \\
\hline & Female & $4.28^{b}$ & \\
\hline
\end{tabular}

Note. Significant sub-group differences are denoted with superscripts such that ${ }^{\mathrm{a}}$ is different from ${ }^{\mathrm{b}}$. 


\section{Self-Determination Through Circus Arts}

Figure 1. Gender and Age Differences in Youth Development Outcomes: Interaction Effects

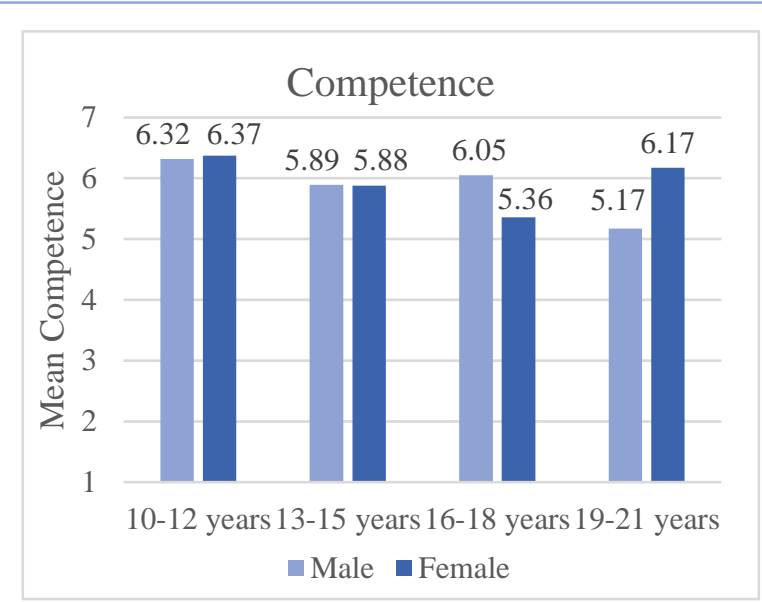

$F(3,95)=5.63, p<.01, \eta^{2}=.15$. Significant gender difference at ages $16-18$ and 19-21

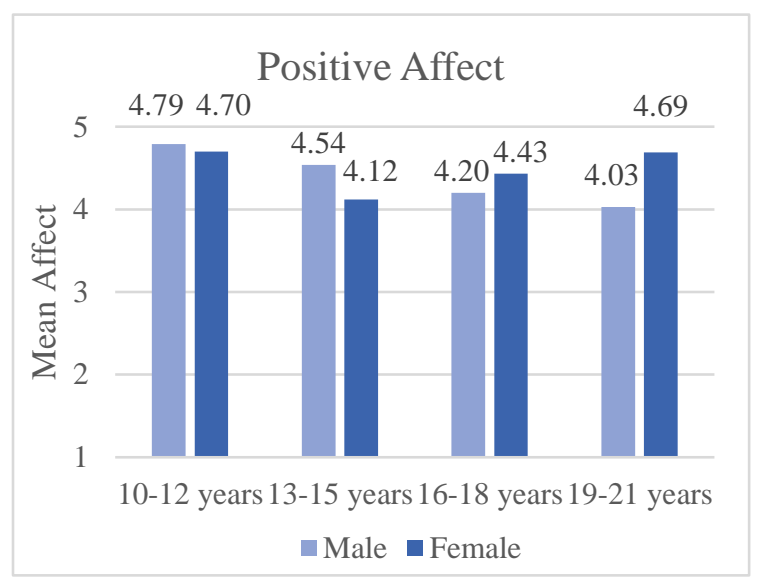

$F(3,94)=4.18, p<.01, \eta^{2}=.12$. Significant gender difference at ages 19-21

\section{Hierarchical Regression Analyses}

To determine whether need satisfaction predicted youth outcomes, a series of hierarchical multiple regression analyses was conducted. In all analyses, gender and age were entered in step 1 to control for their effects, and the three psychological needs were entered in step 2. Relatedness was found to be a significant predictor of many outcomes (Table 3). Relatedness was the stronger predictor of positive affect, but competence also accounted for a significant proportion of variance. Relatedness and competence also accounted for a significant proportion of variance of intrinsic motivation. Further, relatedness and autonomy emerged as significant negative predictors of negative affect, with relatedness being the strongest. For grit and concentration, competence was a significant predictor, along with gender for concentration, and age for grit. For PYD, the effect of all three needs was significant, but relatedness tended to account for more of the variance. 
Journal of Youth Development | http://jyd.pitt.edu/ | Vol. 14 Issue 3 DOI 10.5195/jyd.2019.662 Self-Determination Through Circus Arts

Table 3. Hierarchical Regression Analysis Predicting Intrinsic Motivation, Positive Affect, and Negative Affect From the Three Psychological Needs.

\begin{tabular}{|c|c|c|c|c|c|c|}
\hline Step & Variable & $\begin{array}{c}\text { Standardized } \\
\beta\end{array}$ & $R^{2}$ & $R^{2}$ change & F change & $\begin{array}{l}\text { Significance } \\
\text { of } F \text { change }\end{array}$ \\
\hline \multicolumn{7}{|c|}{ Intrinsic motivation } \\
\hline \multirow[t]{2}{*}{1} & Gender & .037 & .007 & .007 & .343 & .711 \\
\hline & Age & -.075 & & & & \\
\hline 2 & $\begin{array}{l}\text { Autonomy } \\
\text { Competence } \\
\text { Relatedness }\end{array}$ & $\begin{array}{l}.179 \\
.223^{*} \\
.208^{*}\end{array}$ & .186 & .179 & 7.100 & .000 \\
\hline \multicolumn{7}{|c|}{ Positive Affect } \\
\hline \multirow[t]{2}{*}{1} & Gender & .120 & .023 & .023 & 1.166 & .316 \\
\hline & Age & -.097 & & & & \\
\hline 2 & $\begin{array}{l}\text { Autonomy } \\
\text { Competence } \\
\text { Relatedness }\end{array}$ & $\begin{array}{l}-.070 \\
.352 * * * \\
.505 * * *\end{array}$ & .479 & .456 & 27.967 & .000 \\
\hline \multicolumn{7}{|c|}{ Negative Affect } \\
\hline \multirow[t]{2}{*}{1} & Gender & .026 & .011 & .011 & .558 & .574 \\
\hline & Age & .102 & & & & \\
\hline 2 & $\begin{array}{l}\text { Autonomy } \\
\text { Competence } \\
\text { Relatedness }\end{array}$ & $\begin{array}{l}-.296 * * \\
-.076 \\
-.323 * * \\
\end{array}$ & .271 & .259 & 11.377 & .000 \\
\hline \multicolumn{7}{|l|}{ Grit } \\
\hline \multirow[t]{2}{*}{1} & Gender & .108 & .059 & .059 & 3.142 & .047 \\
\hline & Age & $.226 *$ & & & & \\
\hline 2 & $\begin{array}{l}\text { Autonomy } \\
\text { Competence } \\
\text { Relatedness }\end{array}$ & $\begin{array}{l}.004 \\
.244 * \\
.108\end{array}$ & .145 & .086 & 3.245 & .025 \\
\hline
\end{tabular}


Table 3 (continued)

\begin{tabular}{|c|c|c|c|c|c|c|}
\hline Step & Variable & $\begin{array}{c}\text { Standardized } \\
\beta\end{array}$ & $R^{2}$ & $R^{2}$ change & Fchange & $\begin{array}{l}\text { Significance } \\
\text { of } \boldsymbol{F} \text { change }\end{array}$ \\
\hline \multicolumn{7}{|c|}{ Concentration } \\
\hline \multirow[t]{2}{*}{1} & Gender & $.215^{*}$ & .045 & .045 & 2.359 & .100 \\
\hline & Age & -.011 & & & & \\
\hline 2 & $\begin{array}{l}\text { Autonomy } \\
\text { Competence } \\
\text { Relatedness }\end{array}$ & $\begin{array}{l}.179 \\
.247 * \\
.079\end{array}$ & .169 & .123 & 4.751 & .004 \\
\hline \multicolumn{7}{|l|}{ PYD } \\
\hline \multirow[t]{2}{*}{1} & Gender & .158 & .028 & .028 & 1.458 & .238 \\
\hline & Age & -.035 & & & & \\
\hline 2 & $\begin{array}{l}\text { Autonomy } \\
\text { Competence } \\
\text { Relatedness }\end{array}$ & $\begin{array}{c}.161 \\
.134 \\
.197(p=.07)\end{array}$ & .143 & .115 & 4.341 & .006 \\
\hline
\end{tabular}

Note. $N=103$ (intrinsic motivation), $N=102$ (pos. \& neg. affect; grit, concentration); Gender: $0=$ males, 1 = females; PYD = positive youth development; $* p<0.05, * * p<0.01, * * * p<0.001$

\section{Discussion}

This study examined psychological need satisfaction in the context of youth circus, an understudied type of physical activity. In sport and physical education contexts, psychological need satisfaction is known to foster intrinsic motivation and lead to beneficial outcomes such as positive affect and well-being (Standage et al., 2005; Vazou et al., 2006). However, physical activity contexts such as circus arts, whose characteristics may support youth development in different ways (e.g., supportive and cognitively engaging; Diamond, 2015; high levels of trust; Cadwell, 2018), remain unexplored.

In the present study, hierarchical regression analyses controlling for age and gender showed that psychological need satisfaction in the circus context positively predicted positive outcomes such as grit and PYD, as expected based on prior research in youth circus (e.g., Ott, 2005; Smith et al., 2017; Woodhead, 2002). Psychological need satisfaction also positively predicted concentration and positive affect, and negatively predicted negative affect, as observed in other physical activity contexts (Ntoumanis, 2005). In addition, relatedness emerged as a strong 


\section{Self-Determination Through Circus Arts}

predictor, especially of intrinsic motivation, positive and negative affect, and PYD. This finding stands in contrast to previous work in physical education and sport that have focused mainly on support for competence and autonomy (e.g., Reinboth et al., 2004; Shen et al., 2007). In fact, some researchers have asserted that relatedness may be a necessary supportive component only for individuals who are new to exercise (Wilson, Longley, Muon, Rodgers, \& Murray, 2006) while other studies have shown relatedness to be important for intrinsic motivation in physical activity settings (Cox, Duncheon, \& McDavid, 2009; Sparks et al., 2015). There is also considerable support for the influence of family and peers on youth sport participation (Howie, Daniels, \& Guagliano, 2018).

Thus, relatedness may be more important in some activity contexts than others (e.g., contexts involving more teamwork) (Gunnell, Crocker, Wilson, Mack, \& Zumbo, 2013). For example, relatedness has been shown to predict well-being in youth sport (Adie, Duda, \& Ntoumanis, 2012) and performing arts (Quested \& Duda, 2011), but not for solitary exercisers (McAuley et al., 1989). The present study highlights the need for continued study of psychological need support across diverse physical activity contexts, and points to cooperative and team-oriented physical activities as a potential method for youth programs to support relatedness. Circus arts activities are ideal for supporting relatedness in that they are non-competitive and require youth participants to build trusting relationships in order to successfully engage in the activities (Cadwell, 2018). Youth programs focusing on other types of physical activity could develop games or exercises that follow a similar relatedness-supporting ethos.

Our results also identified gender differences in concentration, with girls exhibiting higher levels of consistency and focus than boys, but no gender main effects were observed in other outcomes or in the satisfaction of basic psychological needs. This finding is consistent with the previously observed gender invariance of motivational models based in SDT (Standage et al., 2005). In addition, circus training may provide gender-neutral opportunities for the development of motor competence (Kiez, 2015) that may help to offset the widely-observed lower levels of physical activity among females (Telford et al., 2016). For example, youth in our study engaged most frequently in various types of acrobatics, juggling, aerial, and balance activities in a mixed-gender environment. As such, it is reasonable that few gender differences would be observed in outcomes among youth engaged in circus arts, although gender differences have been observed in sport participation (Hanrahan \& Cerin, 2009).

Finally, age differences were observed in this study for autonomy and competence but not relatedness, with younger youth reporting less autonomy and more competence and positive 


\section{Self-Determination Through Circus Arts}

affect in their circus contexts than older peers. The finding of higher self-reported competence among younger youth may be linked to cognitive differences in self-assessment, as older participants often place larger emphasis on peer comparison when assessing their own competence (Horn, 2004). In addition, competence and positive affect showed interaction effects between age and gender, such that both declined steadily for males and had a U-shaped distribution for females. Further research should assess whether these age and gender differences are unique to youth circus, or to this particular sample. For practitioners however, this finding points to the importance of attending to youth perceptions of their competence in program activities and providing scaffolding for all youth to feel successful.

Overall, the present study highlights the importance of relatedness in youth physical activity contexts for youth development outcomes such as PYD and intrinsic motivation, and points to youth circus as a supportive context for relatedness and other basic psychological needs. These findings align with prior research showing youth circus programs to promote various positive developmental outcomes (e.g., Heller \& Taglialatela, 2018; McCutcheon, 2003; Ott, 2005; Smith et al., 2017; Woodhead, 2002) and suggest the need for further research outside the typical silos of youth development programs and physical education or sport programs. Future studies should examine how features that distinguish youth circus from more commonly-studied physical activity contexts may contribute to the support of relatedness. Youth program leaders may benefit from considering novel ways to engage youth in physical activity while promoting PYD and supporting basic psychological needs, whether or not they include circus arts. Schoolbased physical education programs should also consider incorporating youth circus to provide physical activities that satisfy basic psychological needs (see Kiez, 2015). The finding that this non-sport form of physical activity was associated with need-satisfaction and positive developmental outcomes for youth suggests that offering alternative forms of active recreation in youth programs may be beneficial. However, further research is needed to determine what features of the youth circus context are associated with these outcomes.

\section{Limitations and Future Directions}

The present study has several limitations, including a small convenience sample. Future studies of youth circus should seek larger and more homogeneous samples. The sample in this study represented youth with a wide range of ages, experience levels, and skills, but the small number of youth in each of these categories limited our analytic possibilities. The study also used a cross-sectional design that did not allow us to examine youth development as a result of participation in circus. Further research should be conducted to examine longitudinal outcomes 


\section{Self-Determination Through Circus Arts}

associated with participation in this unique physical activity context, and how youth circus settings impact youth development. Future research should also examine the contextual characteristics that support relatedness in this and other physical activity contexts.

\section{Conclusions}

This study expands the youth development literature by assessing participant outcomes in the under-studied context of youth circus. In addition, in a departure from prior studies that deemphasize relatedness in physical activity (e.g., Wilson et al., 2006), results from the present study point to relatedness as the strongest predictor of positive youth outcomes within the youth circus context. Unique characteristics of the circus context may make relatedness more salient than in other physical activity contexts. Thus, continued research into alternative physical activity contexts, such as circus arts, would be extremely valuable for understanding the effects of different contextual characteristics on youth development. Finding ways for physical activity programs to support relatedness (e.g., through collaborative activities like those in youth circus) may be key for youth physical activity adoption and maintenance. From an educational and a health perspective, it is worth considering whether including youth circus activities in physical education, or otherwise expanding access to this type of activity through youth programs, would help children acquire positive experiences that will help them be more physically active throughout their lives. Considerable further research on youth circus from a developmental perspective is therefore warranted.

\section{Acknowledgements}

The research reported in this manuscript was conducted while the second author was a graduate student at the University of British Columbia. This research was supported in part through the second author's Izaak Walton Killam Memorial Doctoral Fellowship, and University of British Columbia International Tuition Award, Faculty of Graduate Studies Award, and Four Year Fellowship.

\section{Declaration of Interests}

The first and second authors are, respectively, current and founding board members of the American Youth Circus Organization. 
Journal of Youth Development | http://jyd.pitt.edu/ | Vol. 14 Issue 3 DOI 10.5195/jyd.2019.662

\section{Self-Determination Through Circus Arts}

\section{References}

American Youth Circus Organization / American Circus Educators. (2018). 2018 U.S. Circus Survey. Retrieved from: https://www.americancircuseducators.org/resources-2/.

Adie, J. W., Duda, J. L., \& Ntoumanis, N. (2012). Perceived coach-autonomy support, basic need satisfaction and the well-and ill-being of elite youth soccer players: A longitudinal investigation. Psychology of Sport and Exercise, 13(1), 51-59. doi:10.1016/j.psychsport.2011.07.008

Balish, S. M., McLaren, C., Rainham, D., \& Blanchard, C. (2014). Correlates of youth sport attrition: A review and future directions. Psychology of Sport and Exercise, 15, 429-439. doi:10.1016/j.psychsport.2014.04.003

Bolton, R. (2004). Why circus works. (Unpublished doctoral dissertation.) Perth, Australia: Murdoch University.

Cadwell, S. J. (2018). Falling together: An examination of trust-building in youth and social circus training. Theatre, Dance and Performance Training, 9(1), 19-35. doi:10.1080/19443927.2017.1384755

Cox, A., Duncheon, N., \& McDavid, L. (2009). Peers and teachers as sources of relatedness perceptions, motivation, and affective responses in physical education. Research Quarterly for Exercise and Sport, 80(4), 765-773. doi:10.1080/02701367.2009.10599618

Deci, E.L., \& Ryan, R.M. (2000). The "What" and "Why" of goal pursuits: Human needs and the selfdetermination of behavior. Psychological Inquiry, 11(4), 227-268. doi:10.1207/S15327965PLI1104_01

Diamond, A. (2015). Effects of physical exercise on executive functions: Going beyond simply moving to moving with thought. Annals of Sports Medicine and Research, 2(1), 1011.

Duckworth, A. L., Peterson, C., Matthews, M. D., \& Kelly, D. R. (2007). Grit: Perseverance and passion for long-term goals. Journal of Personality and Social Psychology, 92(6), 1087-1101. doi:10.1037/0022-3514.92.6.1087

Ebbeck, V., \& Weiss, M. R. (1998). Determinants of children's self-esteem: An examination of perceived competence and affect in sport. Pediatric Exercise Science, 10, 285-298. doi:10.1123/pes.10.3.285

Evans, M. B., Allan, V., Erickson, K., Martin, L. J., Budziszewski, R., \& Côté, J. (2017). Are all sport activities equal? A systematic review of how youth psychosocial experiences vary across differing sport activities. British Journal of Sports Medicine, 51(3), 169-176. doi:10.1136/bjsports-2016096725

Gagne, M., Ryan, R. M., \& Bargmann, K. (2003). Autonomy support and need satisfaction in the motivation and well-being of gymnasts. Journal of Applied Sport Psychology, 15(4), 372-390. doi:10.1080/714044203 
Journal of Youth Development | http://jyd.pitt.edu/ | Vol. 14 Issue 3 DOI 10.5195/jyd.2019.662

\section{Self-Determination Through Circus Arts}

Geldhof, G. J., Bowers, E. P., Boyd, M. J., Mueller, M. K., Napolitano, C. M., Schmid, K. L., . . \& Lerner, R. M. (2014). Creation of short and very short measures of the five Cs of positive youth development. Journal of Research on Adolescence, 24(1), 163-176. doi:10.1111/jora.12039

Goudas, M., Biddle, S., \& Fox, K. (1994). Perceived locus of causality, goal orientations, and perceived competence in school physical education classes. British Journal of Educational Psychology, $64(3), 453-463$.

Gunnell, K. E., Crocker, P. R., Wilson, P. M., Mack, D. E., \& Zumbo, B. D. (2013). Psychological need satisfaction and thwarting: A test of basic psychological needs theory in physical activity contexts. Psychology of Sport and Exercise, 14(5), 599-607. doi:10.1016/j.psychsport.2013.03.007

Hanrahan, S. J. \& Cerin, E. (2009). Gender, level of participation, and type of sport: Differences in achievement goal orientation and attributional style. Journal of Science and Medicine in Sport, 12(4), 508-512. doi:10.1016/j.jsams.2008.01.005

Harwood, C. G., Keegan, R. J., Smith, J. M., \& Raine, A. S. (2015). A systematic review of the intrapersonal correlates of motivational climate perceptions in sport and physical activity. Psychology of Sport and Exercise, 18, 9-25. doi:10.1016/j.psychsport.2014.11.005

Heller, C., \& Taglialatela, L. A. (2018). Circus Arts Therapy ${ }^{\circledR}$ fitness and play therapy program shows positive clinical results. International Journal of Play Therapy, 27(2), 69. doi:10.1037/pla0000068

Horn, T. S. (2004). Developmental perspectives on self-perceptions in children and adolescents. In M.R. Weiss (Ed.), Developmental sport and exercise psychology: A lifespan perspective (pp. 101-143). Morgantown, WV: Fitness Information Technology.

Howie, E. K., Daniels, B. T., \& Guagliano, J. M. (2018). Promoting physical activity through youth sports programs: It's social. American Journal of Lifestyle Medicine, doi:10.1177/1559827618754842

Kiez, T. K. M. (2015). The Impact of Circus Arts Instruction on the Physical Literacy of Children in Grades 4 and 5. Unpublished master's thesis. University of Manitoba.

Lerner, J. V., Bowers, E. P., Minor, K., Boyd, M. J., Mueller, M. K., Schmid, K. L., \& Lerner, R. M. (2012). Positive youth development: Processes, philosophies, and programs. In R. M. Lerner, M A. Easterbrooks , \& J. Mistry (Eds.), (2011) \& I. B. Weiner ( Editor-in-Chief), Comprehensive Handbook of Psychology: Developmental Psychology Vol. 6 (pp. 365-392). New York: Wiley.

Maglio, J., \& McKinstry, C. (2008). Occupational therapy and circus: Potential partners in enhancing the health and well-being of today's youth. Australian Occupational Therapy Journal, 55(4), 287-290. doi:10.1111/j.1440-1630.2007.00713.x

McAuley, E., Duncan, T., \& Tammen, V. V. (1989). Psychometric properties of the Intrinsic Motivation Inventory in a competitive sport setting: A confirmatory factor analysis. Research Quarterly for Exercise and Sport, 60(1), 48-58. doi:10.1080/02701367.1989.10607413

McCutcheon, S. (2003). Negotiating identity through risk: A community circus model for evoking change and empowering youth. Unpublished master's thesis. Victoria, Australia: La Trobe University. 
Journal of Youth Development | http://jyd.pitt.edu/ | Vol. 14 Issue 3 DOI 10.5195/jyd.2019.662

\section{Self-Determination Through Circus Arts}

Neely, K. C., McHugh, T. L. F., Dunn, J. G., \& Holt, N. L. (2017). Athletes and parents coping with deselection in competitive youth sport: A communal coping perspective. Psychology of Sport and Exercise, 30, 1-9. doi:10.1016/j.psychsport.2017.01.004

Nicholls, J. (1989). The competitive ethos and democratic education. Cambridge, MA: Harvard University Press.

Ntoumanis, N. (2005). A prospective study of participation in optional school physical education using a self-determination theory framework. Journal of Educational Psychology, 97(3), 444.

Ott, D. (2005). A phenomenology of youth circus training at Fern Street. (Unpublished doctoral dissertation). Tempe, Arizona: Arizona State University.

Perkins, D. F., \& Noam, G. G. (2007). Characteristics of sports-based youth development programs. New Directions for Youth Development, 115, 75-84. doi:10.1002/yd.224

Quested, E., \& Duda, J. L. (2011). Antecedents of burnout among elite dancers: A longitudinal test of basic needs theory. Psychology of Sport and Exercise, 12(2), 159-167. doi:10.1016/j.psychsport.2010.09.003

Reinboth, M., Duda, J. L., \& Ntoumanis, N. (2004). Dimensions of coaching behavior, need satisfaction, and the psychological and physical welfare of young athletes. Motivation and Emotion, 28(3), 297-313. doi:10.1023/B:MOEM.0000040156.81924.b8

Richer, S., \& Vallerand, R. J. (1998). Construction and validation of the Perceived Relatedness Scale. Revue Européene de Psychologie Appliquée, 48, 129-137.

Roth, J. L., \& Brooks-Gunn, J. (2003). What exactly is a youth development program? Answers from research and practice. Applied Developmental Science, $7(2), 94-111$. doi:10.1207/S1532480XADS0702_6

Shen, B., McCaughtry, N., \& Martin, J. (2007). The influence of self-determination in physical education on leisure-time physical activity behavior. Research Quarterly for Exercise and Sport, 78(4), 328338. doi:10.1080/02701367.2007.10599430

Smith, A. L. (2003). Peer relationships in physical activity contexts: A road less traveled in youth sport and exercise psychology research. Psychology of Sport and Exercise, 4(1), 25-39. doi:10.1016/S1469-0292(02)00015-8

Smith, C., Roy, L., Peck, S., \& Macleod, C. (2017). Evaluation of program quality and social and emotional learning in American Youth Circus Organization social circus programs. Retrieved January 2018 from American Youth Circus Organization website: http://www.americancircuseducators.org/sel/.

Song, M., Carroll, D. D., \& Fulton, J. E. (2013). Meeting the 2008 physical activity guidelines for Americans among US youth. American Journal of Preventive Medicine, 44(3), 216-222. doi:10.1016/j.amepre.2012.11.016 
Journal of Youth Development | http://jyd.pitt.edu/ | Vol. 14 Issue 3 DOI 10.5195/jyd.2019.662

\section{Self-Determination Through Circus Arts}

Sparks, C., Dimmock, J., Whipp, P., Lonsdale, C., \& Jackson, B. (2015). "Getting connected": High school physical education teacher behaviors that facilitate students' relatedness support perceptions. Sport, Exercise, and Performance Psychology, 4(3), 219-236. doi:10.1037/spy0000039

Spiegel, J. B., Breilh, M. C., Campaña, A., Marcuse, J., \& Yassi, A. (2015). Social circus and health equity: Exploring the national social circus program in Ecuador. Arts \& Health, 71$), 65-74$. doi:10.1080/17533015.2014.932292

Standage, M., Duda, J. L., \& Ntoumanis, N. (2003). A model of contextual motivation in physical education: Using constructs from self-determination and achievement goal theories to predict physical activity intentions. Journal of Educational Psychology, 95(1), 97-110. doi:10.1037/00220663.95.1.97

Standage, M., Duda, J. L., \& Ntoumanis, N. (2005). A test of self-determination theory in school physical education. British Journal of Educational Psychology, 75, 411-433. doi:10.1348/000709904X22359

Standage, M., Duda, J. L., \& Ntoumanis, N. (2006). Students' motivational processes and their relationship to teacher ratings in school physical education: A self-determination theory approach. Research Quarterly for Exercise and Sport, 7オ1), 100-110. doi:10.1080/02701367.2006.10599336

Sugarman, R. (2001). Circus for Everyone: Circus Learning Around the World. Mountainside Press.

Teixeira, P. J., Carraça, E. V., Markland, D., Silva, M. N., \& Ryan, R. M. (2012). Exercise, physical activity, and self-determination theory: A systematic review. International Journal of Behavioral Nutrition and Physical Activity, 9-78. doi:10.1186/1479-5868-9-78

Telford, R. M., Telford, R. D., Olive, L. S., Cochrane, T., \& Davey, R. (2016). Why are girls less physically active than boys? Findings from the LOOK longitudinal study. PloS one, 11(3), e0150041. doi:10.1371/journal.pone.0150041

Vallerand, R. J. (2007). Intrinsic and extrinsic motivation in sport and physical activity. Handbook of Sport Psychology, 3, 59-83. doi:10.1002/9781118270011.ch3

Vazou, S., Ntoumanis, N., \& Duda, J.L. (2006). Predicting young athlete's motivational indices from perceived coach and peer climate. Psychology of Sport and Exercise, 7, 215-233.

doi:10.1016/j.psychsport.2005.08.007

Williams, G. C., \& Deci, E. L. (1996). Internalization of biopsychosocial values by medical students: a test of self-determination theory. Journal of Personality and Social Psychology, 70(4), 767-779. doi:10.1037/0022-3514.70.4.767

Wilson, P. M., Longley, K., Muon, S., Rodgers, W. M., \& Murray, T. C. (2006). Examining the Contributions of Perceived Psychological Need Satisfaction to Well-Being in Exercise. Journal of Applied Biobehavioral Research, 11(3-4), 243-264. 
Journal of Youth Development | http://jyd.pitt.edu/ | Vol. 14 Issue 3 DOI 10.5195/jyd.2019.662 Self-Determination Through Circus Arts

Woodhead, P. (2002). Fellowship Report: In-school circus programs in the USA and UK. Winston Churchill Memorial Trust of Australia. Retrieved March 2012, from http://www.churchilltrust.com.au/fellows/detail/2651/ 